\title{
COVID-19 Enfeksiyonu ve Kardiyovasküler Hastalıklar
}

\section{COVID-19 Infection and Cardiovascular Diseases}

\author{
Cenk Ekmekci $\odot$, Öner Özdoğan $\odot$
}

Derleme Review

Alındığı tarih: 08.05 .2020 Kabul tarihi: 27.05 .2020 Online Yayın tarihi: 10.07.2020

Cenk Ekmekci Sağlık Bilimleri Üniversitesi, Tepecik Eğitim ve Araştırma Hastanesi, Kardiyoloji Bölümü, Izmir - Türkiye cenkekmekci@yahoo.com ORCID: 0000-0001-7130-4819

Ö. Özdoğan ORCID: 0000-0003-3205-6917 Sağlık Bilimleri Üniversitesi, Tepecik Eğitim ve Araştırma Hastanesi, Kardiyoloji Bölümü, Izmir, Türkiye

Cite as: Ekmekci C, Özdoğan Ö. COVID-19 Enfeksiyonu ve Kardiyovasküler Hastaliklar. Tepecik Eğit. ve Araşt. Hast. Dergisi. 2020;30(Ek sayı):94-100. öz

COVID-19 enfeksiyona ait bulgular genelde solunum sistemi ile ilişkili olmakla birlikte, hastaların bir kısmında başvuru anında kalp ve damar hastalık bulguları görülmektedir. Ölüm oranının bilinen kalp ve damar hastalıkları olan yaşlılarda en yüksek düzeyde olması nedeniyle COVID-19 pandemisinde kardiyoloji uzmanlarının hastalıkla mücadelede aktif görev almaları zorunlu hâle gelmiştir. Derlememizin amacı, COVID-19'lu hastalarda kalp yetmezliği, akut koroner sendrom, koagülopati ve hipertansiyon tanı ve tedavilerinin yönetimi ile birlikte sahada çalışan tüm tıp doktorlarına karşılaştıkları sorunlar ve sorular hakkında pratik öneriler sunmaktır.

Anahtar kelimeler: COVID-19, kardiyovasküler sistem, hidroksiklorokin, QT uzaması, D-dimer

\section{ABSTRACT}

Although the findings of COVID-19 infection are generally related with the respiratory system, symptoms of cardiovascular disease are observed in some patients at admission. As the highest mortality rate is seen in the elderly with known cardiovascular diseases, cardiologists have to take active parts in dealing with the disease during the COVID-19 pandemic. The purpose of this review is to provide practical advice on the issues and questions that all physicians working in the field can encounter, along with the management and diagnosis of heart failure, acute coronary syndrome, coagulopathy, and hypertension in patients with COVID-19.

Keywords: COVID-19, cardiovascular system, hydroxychloroquine, QT prolongation, D-dimer
Çin Halk Cumhuriyeti'nin Hubei eyaletine bağı $W u h a n ' d a ~ A r a l ı k ~ 2019 ' d a$ yeni bir koronavirüs nedeniyle geliştiği düşünülen pnömoni salgını belirlenmiş ve bu salgın kontrol altına alınamayarak kısa sürede önce Çin'in diğer eyaletlerine sonrada bir pandemiye yol açacak şekilde başta Avrupa kıtası olmak üzere tüm dünyaya yayılmıştır (1). COVID-19 enfeksiyonuna ait bulgular genelde solunum sistemi ile ilişkili olmakla birlikte hastaların bir kısmında kardiyak hastalık bulguları görülmesi dikkatleri kardiyovasküler sisteme (KVS) çekmiştir. Pandemi sürecinin ilerlemesi ile birlikte geniş olgu serilerinden elde edilen veriler incelendiğinde salgından en çok etkilenen ve ölüm oranı en yüksek grubun bilinen kalp ve damar hastalıkları olan yaşlılar olduğu belirlenmiştir (2). Bu nedenle COVID-19 pandemisinde kardiyoloji uzmanlarının salgınla mücadelede aktif görev almaları zorunlu hale gelmiştir. Bu derlemenin amacl, COVID19 'dan etkilenen kalp ve damar hastalarının yönetiminde güncel bilgilerin kısa bir değerlendirmesini yapmak ve COVID-19'la mücadelede sahada görev alan tüm tıp doktorlarına karşılaştıkları sorunlar ve sorular hakkında pratik öneriler sunmaktır.

\section{SARS-CoV-2'nin özellikleri nelerdir?}

SARS-CoV2 virüsü insanlarda akciğer
(C) Telif hakkı T.C. Sağık Bakanlığı İzmir Tepecik Eğit. ve Araşt. Hastanesi. Logos Tıp Yayıncılık tarafindan yayınlanmaktadı. Bu dergide yayınlanan bütün makaleler Creative Commons Attf-GayriTicari 4.0 Uluslararası Lisansı ile lisanslanmıştır.

(c) Copyright Association of Publication of the T.C. Ministry of Health Izmir Tepecik Education and Research Hospital.

This journal published by Logos Medical Publishing.

Licenced by Creative Commons Attribution-NonCommercial 4.0 International (CC BY-NC 4.0) 
Tip 2 alveol hücreleri başta olmak üzere miyokard, özofagus, ileum epitel hücreleri, böbrek proksimal tübül ve mesane üroepitelyal hücrelerinde bulunan anjiyotensin dönüştürücü enzim-2 (ACE2) reseptörüne kolayca bağlanır. En sık görülen semptomlar ateş, yorgunluk, kas ağrısı, boğaz ağrısı, kuru öksürük, daha az sıklıkla bulantı-kusma ve diyaredir. Hastane yatışlarının başlıca nedeni \%91 pnömoni, \%3.4 akut solunum sıkıntısı sendromu (acute respiratory distress syndrome [ARDS]) ve \%1.1 şok tablosudur. Yaşlııı, hipertansiyon (HT), KVS hastalıklar ve diyabet (DM) hastalığın ağır seyretmesine yol açan başıca risk faktörleridir ${ }^{(3)}$.

\section{COVID-19 ve KARDIYOVASKÜLER HASTALIKLAR}

COVID-19 enfeksiyonundan etkilenen hastaların verilerini sunan en kapsamlı raporlardan (72.314 COVID19 hastası) biri Çin Hastalık Kontrol ve Korunma Merkezince hazırlanmıştır. Büyük çoğunluğu (\%87) 30-79 yaş aralığında olan hastalardaki ölüm hızı $\% 2.3$ 'dür. Ölüm oranı 70-79 yaş arasında $\% 8,80$ yaş ve üzerinde ise \%14.8'dir. Eşlik eden hastalıkları olanlarda ölüm oranları genel popülasyona göre daha yüksek; KVS hastalığı olanlarda \%10,5, diyabetiklerde \%7.3, kronik akciğer hastalığı olanlarda \%6.3, HT olanlarda \%6 ve kanser hastalarında \%5.6 olarak saptanmıştır ${ }^{(1)}$. Pandeminin artması ile birlikte İtalya ve Amerika Birleşik Devletleri (ABD)'nden de geniş olgu serilerini içeren yayınlar ortaya çıkmıştır. ABD New York eyaletinde yatarak tedavi gören 5700 COVID-19 hastanın alındığı çalışmada en sık eşlik eden hastalıklar; KVS hastalık [HT (3.026; \%56.6), koroner arter hastalığı (595; \%11,1), kalp yetmezliği (KY) (371; \%6.9)] obezite (1737; \%41.7) ve DM (1808; \%33.8)

Tablo 1. COVID-19'lu hastalarda eșlik eden kardiyovasküler hastalıklar ve risk faktörleri.

\begin{tabular}{lcc}
\hline Hastalık & Sayı & Oran (\%) \\
\hline Hipertansiyon & 3.026 & 56.6 \\
Koroner Arter Hastalığı & 595 & 11.1 \\
Konjestik Kalp Yetmezliği & 371 & 6.9 \\
BMI $\geq 30$ & 1.737 & 41.7 \\
\hline
\end{tabular}

Kaynak:4 saptanmıştır ${ }^{(4)}$ (Tablo 1). Bu geniş olgu serilerinden elde edilen sonuçlara göre COVID-19 enfeksiyonunun KVS üzerinde başlıca 3 etkisi vardır.

1. Eşlik eden KVS hastalığı varlığında, enfeksiyonun ağır seyretme olasılığı ve ölüm riski artar.

2. COVID-19; miyokard hasarı (miyokard infarktüsü, miyokardit, kalp yetmezliği), aritmi ve venöz tromboemboli gibi çok sayıda KVS komplikasyonlarıyla ilişkilidir.

3. COVID-19 tedavisinde mevcut kullanılan ilaçlarla birlikte araştırma ve geliştirme aşamasında olan ilaçlar KVS üzerine çeşitli yan etkilere sahiptir.

Virüsle enfekte olmuş kardiyak hastalarda sonlanım kötüdür. Bunun nedeni; kronik kardiyovasküler sistem hastalarının enfeksiyondan bulaş korkusu ile hastane başvurularını ertelemeleri ya da geciktirmeleridir. Mortalite ile ilişkili en geniş veriler dünya genelinde en yüksek ölüm oranına sahip ülkelerden biri olan İtalya'dan elde edilmiştir. Yaşamını kaybeden 3.200 hastanın incelendiği çalışmada, ortalama yaşın 78.5, erkeklerde ölüm oranının daha yüksek (E/K oranı: 2.35 ) olduğu ve olguların büyük çoğunluğunun KVS hastalığa sahip olduğu görülmüştür. İleri yaş ve erkek cinsiyetin kardiyovasküler sistem hastalıkları içinde başlıca risk faktörleri olması bu sonuçları desteklemiştir ${ }^{(5)}$.

\section{KARDIYAK TROPONINLER}

COVID-19 hastalarının önemli bir kısmında yüksek duyarlıklı kardiyak troponin (hs-cTn) düzeylerinin artmış olduğu bildirilmiştir ${ }^{(1)}$. COVID-19'lu 191 olgunun incelendiği bir çalışmada, ölenlerin \%50'sinden fazlasında hs-cTnl düzeylerinin; başvuru anında yüksek olduğu, hastaların kaybedildiği güne kadar tedrici olarak yükseldiği ve mortalitenin önemli bir göstergesi olduğu saptanmıştır. Ölümle sonlanan olgular arasında hs-cTnl $>28 \mathrm{mg} / \mathrm{ml}$ düzeyleri oranı $\% 46$ iken, yaşayan hastalarda bu oran \%1 saptanmıştır $(p<0.0001)^{(6)}$. Troponin artışının mekanizması tam olarak anlaşılamamıştır. ARDS'nin direkt miyokardda 
neden olduğu hasar, enflamasyonun tetiklediği prokoagülan sistem aktivasyonu ve plak rüptürü ile ortaya çıkan tip I miyokard infarktüsü (MI), ciddi enflamasyon nedeni ile miyokardda ortaya çıkan oksijen arz-talep dengesizliğine bağlı tip II (sekonder) MI olası senaryolardır. Ayrıca miyositler ve vasküler endotel hücrelerinde bol miktarda bulunan ve koronavirüsün bağlandığı bölge olan ACE2'nin virüs tarafından invazyonu; doğrudan kardiyak tutulumun nedeni olabileceği öne sürülmektedir. COVID-19 enfeksiyonu sırasında tek başına troponin yüksekliği akut koroner sendrom (AKS) tanısı koydurmaz. AKS tanısı için kesinlikle diğer klinik özelliklerin (semptom, CKMB, EKG) aranması önerilir. AKS veya miyokard hasarı ile ilgili diğer klinik bulguların olmadığı durumlarda troponin bakılması önerilmemektedir.

Tip I MI dışında tek başına troponin yüksekliğinde antiplatelet ve antikoagülan tedavi başlanma endikasyonu yoktur. Ancak, klinik açıdan kötü seyreden özellikle yoğun bakım hastalarında prognoz tayini amacıyla troponin düzeylerine bakılabilir ${ }^{(7)}$.

\section{NATRIÜRETIK PEPTIDLER}

Natriüretik peptidler (NP), KY veya ciddi solunum yetmezliğinde yükselebilen biyobelirteçlerdir ${ }^{(8)}$. COVID-19 enfeksiyonlu hastalarda B tipi NP düzeylerinde artış olduğu saptanmakla birlikte, diğer klinik bulgular olmadıkça yalnızca B tipi NP yüksekliğinin KY tanısı koymak için yeterli olmadığı bildirilmiş$\operatorname{tir}^{(9)}$.

\section{D-DIMER}

COVID-19 olgularının yaklaşık yarısında yüksek bulunmuştur. Hastane içi mortalitenin bağımsız bir öngördürücüsü olarak saptanmıştır. D-dimer artışı, yüksek sistemik enflamatuvar aktivasyonun prokoagülan süreci tetiklemesine bağı olabilir. Sonuç olarak, mikrovasküler yataktaki arterio-venöz pulmoner emboli ile ilişkilendirilen $d$-dimer yüksekliğine yönelik antikoagülan tedavi önerilmektedir ${ }^{(6)}$.

\section{MIYOKARDIT}

COVID-19 enfeksiyonu doğrudan miyokardit gelişimiyle kardiyak hemodinamiyi ciddi şekilde bozabilir. Bununla birlikte, virüsün doğrudan miyokard infiltrasyonu yaptığına dair kanıtlar henüz yeterli değildir. COVID-19 hastalarında sıklıkla troponin yüksekliği görülmekle birlikte, tek başına yüksekliği miyokardit tanısı için yeterli değildir. Miyokarditin eşlik ettiği COVID-19 hastalarında troponin ile birlikte IL-6 ve NP'de de anlamlı yükselme olduğu, ekokardiyografide sol ventrikül ejeksiyon fraksiyonunun ileri derecede azaldığı bildirilmiştir ${ }^{(10)}$. Fulminan miyokarditli hastalarda pozitif inotrop tedavinin yanı sıra kortikosteroid ve IVIG tedavisinin kullanılması önerilebilir ${ }^{(11)}$.

\section{COVID-19 ve HIPERTANSIYON}

COVID-19 enfeksiyonunda hipertansiyon mortalite için önemli bir risk faktörüdür ${ }^{(1-12)}$. ACE2 reseptörleri, COVID-19'a neden olan SARS-CoV-2 virüsünün insan hücrelerine giriş noktasıdır ${ }^{(13)}$. ACE2, ACE'nin bir homoloğudur. ACE2, Anjiyotensin II'yi kan damarlarını genişleten Anjiyotensin 1-7'ye dönüştürerek, anjiyotensin II'nin vazokonstrüksiyon etkisini azaltmakta ve renin anjiyotensin sistemini negatif yönde regüle etmektedir ${ }^{(14)}$. Hayvan modelleri ile yapılan birkaç deneysel çalışmada, hem ACE inhibitörlerinin hem de anjiyotensin reseptör blokerlerinin (ARB) kalpteki ACE2 ekspresyonunu upregüle ettiği görülmüştür. İnsan çalışmalarında teyit edilmemesine rağmen, ACE2'nin, RAAS (Renin Anjiotensin Aldosteron Sistem) blokerleri (ACE inhibitörleri veya ARB'ler) tarafından potansiyel upregülasyonu; bu ilaçlarla HT ya da KY tedavisi gören hastalarda COVID-19 enfeksiyon riskini yükselttiğine dair tartışmalar mevcuttur. Fakat yakın zamanda yapılan deneysel çalışmalarda, hem ACE inhibitörlerinin hem de ARB'lerin viral pnömonilerde ciddi akciğer hasarını azalttığı gösterilmiş ve bu ilaçların COVID-19 için faydalı olabileceği düşünülmüştür. Şu anda $A C E$ inhibitörleri ve $A R B^{\prime}$ lerin kardiyovasküler hastalık öyküsü olan COVID-19 has- 
talarında kullanımına dair olumlu veya olumsuz sonuçlar ortaya koyan deneysel veya klinik hiçbir veri mevcut değildir. Hem ABD hem de Avrupa Kalp Cemiyeti Kılavuzları (HFSA, ACC, AHA, ESC) hâlihazırda $\mathrm{KY}$, HT veya iskemik kalp hastalığı gibi durumlarda uygun endikasyonlarda ACE inhibitörleri ve ARB'lerin kullanımına devam edilmesini önermektedir ${ }^{(15,16)}$.

\section{COVID-19 ve Koroner Sendromlar}

\section{İnvaziv ve noninvaziv yaklaşımlar}

Literatürde COVID-19 pozitifliği nedeniyle hastaneye yatırılan hastaların \%40'ında kardiyovasküler veya serebrovasküler hastalık öyküsü olduğu, tanı anında ve izlemlerinde ise $\% 17$ 'sinde aritmi ve $\% 7$ 'sinde de akut kardiyak hasar olduğu gözlenmiştir. Akut kardiyak hasar tanımlı kabul edilen COVID-19'lu hastaların klinik prezantasyonu; akut KY, akut MI, miyokardit ve ani kardiyak arrest olmak üzere 4 şekilde gözlenmiştir ${ }^{(1,2)}$. Kardiyak hasarı gösteren enzim yüksekliği (hs-cTn) tek başına akut kardiyak hasar-özellikle akut MI- tanısı için yetersizdir. Tanı için semptom, EKG ve CKMB yüksekliğinin de aranması şarttır. COVID-19 seyrinde kardiyak enzim yüksekliği ve miyokard hasarının en olası nedeni, virüsün neden olduğu doğrudan miyokard hasarıdır ${ }^{(1,7)}$. SARS-CoV-2'nin bağlanma noktası olan ACE2'nin kardiyak miyosit hücrelerindeki yoğun dağılımı nedeniyle virüsün bu hücrelere yüksek affinitesi ve dolayısıyla yol açtığı harabiyet; miyokardite yol açarak troponindeki yükselmeden sorumlu tutulmaktadır. Ancak tek başına hs-cTn yüksekliği de COVID-19'lu bir hastada miyokardit tanısını doğrudan koyduramaz. Bu hastalarda ekokardiyografinin tanıyı desteklemesi gerekmektedir ${ }^{(10,11)}$. Diğer tüm akut kardiyak hasar tanılarında da hastanın özellikle semptomlarının (göğüs ağrısı, ayaklarda şişlik, efor kapasitesinde azalma) sorgulanması, EKG bulgularının kontrol edilmesi ve CKMB çalışılması önemlidir. Pandemi ile ilişkili kılavuzlarda COVID-19 tanı ve/ veya kuşkusu ile başvuran hastalarda rutin olarak troponin istenmemesi ancak klinik bulgular gerektiriyorsa bu testlerin yapılması önerilmiştir.
COVID-19 enfeksiyonu ile birlikte kesin AKS tanıSı alan hastalarda; Avrupa ve Amerika Kalp derneklerinin kılavuzlarında enfeksiyondan korunma tedbirlerinin yeterli olmadığı kateter laboratuvarı şartlarında girişimsel olmayan tedavilerin (Örneğin, ST eleve MI'da trombolitik tedavi) uygulanması ön plana çıkmıştır. Tüm sağlık personelinin enfeksiyondan korunma önlemlerinin maksimum seviyede alınması şartıyla ST eleve MI'da invaziv tedavi (koroner anjiografi ve primer perkütan koroner girişim) önerilmektedir. ST elevasyonsuz Ml'da ise noninvaziv izlem (maksimal medikal tedavi) önerilmekle birlikte bu hasta grubunda, a) ilaç tedavisine dirençli göğüs ağrısı, b) yaşamı tehdit eden ventriküler aritmiler, c) hemodinamik instabil durum, d) kardiyak arrest parametrelerinden birinin varlığında erken invaziv girişim önerilmektedir ${ }^{(17,18)}$.

\section{COVID-19 ve KALP YETMEZLiĞi}

COVID-19 enfeksiyonunda en sık ikinci semptom olan nefes darlığı ile birlikte gerek virüsün miyokarda direkt hasarı gerekse mikrovasküler hasar nedeniyle ortaya çıkan EKG değişiklikleri (ST elevasyonu, ST depresyonu-ST Strain gibi nonspesifik ST/T değişiklikleri) ve kardiyak enzimlerde yükselme (troponin, D-dimer ve NP düzeyleri) hastaların AKS ve KY ön tanıları ile kardiyolojiye yatışına yol açabilir. COViD19 tanısı ile hastaneye yatırılan hastaların \%10'unda KY gelişmiştir. Kalp yetmezliği; COVID-19'lu hastalarda önemli bir başvuru şekli ve ölüm nedeni olmakla birlikte, yoğun bakım yatış sürecini uzatmakta ve kötü sonlanımlara (böbrek yetmezliği, ARDS) yol açmaktadır. Çin'den gelen ilk olgu serilerinin yayınlandığı Zhou ve ark. çalışmasında, tüm hasta grubunun \%23'ünde, ölümle sonuçlanan hastaların ise $\% 52$ 'sinde kalp yetmezliği olduğu saptanmıştır. COVID-19 hastalarındaki KY ile ilişkili olarak; altta yatan KY'nin alevlenmesi ya da yeni bir KY tablosunun geliştiğine dair tartışmalar henüz açıklığa kavuşmamıştır ${ }^{(1-6)}$. COVID-19 hastalarında yapılan görüntülemede (Toraks BT) buzlu cam manzarasının eşlik ettiği ve ARDS'ye ilerleyebilen klinik tablo akut KY ile 
oldukça karışır. Ekokardiyografi ve NP seviyeleri ile ayırıcı tanıya gitmek olasıdır ${ }^{(19)}$. Hastaların kullandığı RAAS blokerleri ile ilgili mortalite üzerine etkisi kesinleşmiş tedavilerinin kesilmesini gerektirecek kesin bir kanıt bulunmadığından uygun şartlarda ilaçlara devam edilmelidir. Ayrıca endikasyon dahilinde betabloker ve diüretiklerde tedaviye eklenmelidir. KY olan tüm hastalarda grip ve pnömoni aşıları COVID19 enfeksiyonunu önlemese de oluşabilecek ikincil enfeksiyonları önlemede önemli oldukları için önerilmelidir ${ }^{(20)}$.

\section{COVID-19 TEDAVISI ile KARDIYAK ILAÇLARIN ETKILEŞiMi}

COVID-19 enfeksiyonu tedavisinde hidroksiklorokin, azitromisin, lopinavir ve ritonavir yaygın olarak kullanılmaktadır ${ }^{(21)}$. Antiviral olarak kullanılan lopinavir ve ritonavirin en önemli yan etkileri EKG'de PR uzaması ve atriyoventriküler blok ile ortaya çıkan iletim sistemi bozukluklarıdır. Tedavi öncesi ve sonrası izlemde hastanın EKG takibi önemlidir. Hidroksiklorokinin yan etkileri akut ve kronik kullanımda farklılıklar gösterir.
COVID-19 hastalarında kullanılan yüksek dozlarda; kalpteki $\mathrm{Na} / \mathrm{K} / \mathrm{Ca}$ kanal blokajına bağlı ileti sistemi bozuklukları (QT uzaması, AV blok, dal blokları) yanısıra negatif inotropik etki ve periferik vazodilatasyonu içeren akut etkilerdir. Kronik kullanımda sol ventrikül hipertofisi en sık yan etkisidir. Özellikle akut kullanımda QT'yi uzatan ilaçlar (amiodaron, ve sotalol gibi antiaritmikler, makrolidler, antihistaminikler, antipsikotikler), kalp ileti sistemine etkili ilaçlar (betablokerler, kalsiyum kanal blokerleri, digoksin) ve elektrolitler (özellikle potasyum, magnezyum, kalsiyum) dikkatli sorgulanmalıdır. Hidroksiklorokinin en korkutucu yan etkisi QT aralığını uzatıp ventriküler taşikardiye (Torsades de pointes) eğilim yaratmasıdır. Özellikle ileri yaşlı, kardiyak komorbiditesi olan, QT'yi uzatan başka ilaç kullanan, elektrolit bozuklukları olan hastalarda bu risk daha yüksektir ${ }^{(22,23)}$. Bu nedenle COVID-19 nedeniyle hidroksiklorokin başlanacak veya almakta olan hastalarda QT uzaması açısından risk değerlendirmesi ${ }^{(24)}$ ve gereğinde kardiyoloji konsültasyonu yapılarak karar verilmesi gereklidir (Resim 1).

Hidroksiklorokin monoterapisi \pm Kombine kullanım(Makrolid/Antiviral)

Tedavi başlangıcı QTc hesaplanması*

ilk doz sonrası 3. saat QTc hesaplanması

EKG takiplerindeki QTc ölçümlerinde



- Serum elektrolitlerinin (özellikle potasyum) kontrolü

- QT'yi uzatabilen diğer ilaçların yakın takibi ve sorgulanması

\section{* :QTC: QT $/ \sqrt{R R}$}




\section{COVID-19 Ve KOAGÜLOPATI}

COVID-19 seyrinde tromboembolik olay gelişimine yol açan mekanizmalar;

1. Virüsün ACE2'ye bağlanması ile ve/veya doğrudan endotelde yaptığı hasar ile ilişkili

2. Sepsisde gözlenen vasküler mikrotrombotik hastalık ilişkili (kompleman aktivasyonu ile endotel hasarı ve inflamatuvar ve mikrotrombotik yolak aktivasyonu)

3. Hastanede yatış/immobilizasyon ilişkili venöz staz

Çin'de Wuhan'dan bildirilen deneyimlerde koagülopati, vireminin genellikle 7. gününde belirginleşmiş ve koagülopati gelişen hastalarda ölüm daha sık izlenmiştir. Virüsün ACE2 ekspresyonunda azalmaya yol açması ile RAS yolağı aktifleşmektedir. RAS aktivasyonu trombosit adezyonu ve agregasyonunu uyarması ile pulmoner emboli, pulmoner hipertansiyon ve pulmoner fibrozis riski artmaktadır. Plazma doku faktörü ve plazminojen aktivatör inhibitor-1, ARDS gelişmiş hastalarda ARDS gelişmemiş hastalara göre daha yüksek bulunmuştur. Tüm COVID-19 hastalarına tanı konulması ile birlikte koagülopati izlemi (d-dimer takibi) başlatılmalı ve heparin profilaksisi uygulanmalıdır. COVID-19'lu hastalarda heparin kullanımı ile mortalitenin belirgin azaldığı gösterilmiştir. Heparinin bu başarısında antikoagülan etkisi yanı sıra inflamatuvar sitokinleri bağlaması, nötrofil kemotaksisini ve lökosit migrasyonunu inhibe etmesi, pozitif yüklü peptit C5a'yı nötralize etmesi ve akut faz proteinlerini sekestre etmesinin rolünden söz edilmektedir (1,2). Sağlık Bakanlığı COVID-19 (SARS-CoV-2 ENFEKSIYONU) REHBERI (14.04.2020) Bilim Kurulu çalışmasında tromboemboli profilaksisi ile ilişkili öneriler ayrıntılı olarak sunulmuştur ${ }^{(25)}$.

\section{1) D-dimer $<1000 \mathrm{ng} / \mathrm{ml}$ olan hastalarda tromboz profilaksisi Kreatinin klirensi > $\mathbf{3 0 ~} \mathbf{~ m l} / \mathbf{d k}$. \\ $\mathrm{BMI}<40 \mathrm{~kg} / \mathrm{m}^{2}$ : Enoksaparin $40 \mathrm{mg} 1 \times 1 \mathrm{sc}$ \\ $\mathrm{BMI} \geq 40 \mathrm{~kg} / \mathrm{m}^{2}$ : Enoksaparin $40 \mathrm{mg} 2 \times 1 \mathrm{sc}$}

Kreatinin klirensi < $\mathbf{3 0 ~} \mathbf{m l} / \mathbf{d k}$.

Genellikle düşük molekül ağırlıklı heparin (DMAH) önerilmez. Standart heparin $5000 \mathrm{U}$ sc $2 \times 1$ ya da $3 \times 1$ veya doz azaltılmış DMAH önerilir.

\section{2) D-dimer $>1000 \mathrm{ng} / \mathrm{ml}$ veya ağır hastalık hâli olan hastalar}

Enoksaparin: $0.5 \mathrm{mg} / \mathrm{kg} 12$ saatte bir sc

Kreatinin klirensi $<\mathbf{3 0 ~} \mathbf{~ m l} / \mathbf{d k}$.

Standart heparin $5.000 \mathrm{U}$ sc $2 \times 1$ veya $3 \times 1$ veya doz azaltılmış DMAH önerilir.

Atriyal fibrilasyon, inme veya venöz tromboembolizm öyküsü nedeni ile oral antikoagülan kullanan hastalarda DMAH'a geçilmesi düşünülmelidir. Hastanede yatış sırasında başlanan profilaksiye taburculuk sonrası özellikle inflamasyon belirteçleri ya da tromboz riski yüksek hastalarda (lenfopeni, ağır seyreden pnömoni, d-dimer yüksekliği, yaşlı ve/ veya yandaş hastalığı olan hastalar) 1 ay devam edilmelidir. Yatış sırasında klinik olarak aşikar tromboz tanımlanan hastalarda ise 3 ay yüksek doz $(1 \mathrm{mg} / \mathrm{kg})$ enoksaparin 2x1 sc önerilir.

\section{SONUÇ}

Özellikle eşlik eden KVS hastalığı varlığında, COVID19 enfeksiyonu ağır seyretmekte ve ölüm riski artmaktadır. COVID-19 enfeksiyonları miyokard enfeksiyonu, miyokardit, kalp yetersizliği ve aritmilerden venöz tromboemboliye kadar birçok klinik tabloya yol açabilmektedir. Enflamasyon, sitokin fırtınası, artmış pıhtılaşma fonksiyonları yanısıra miyokarda oksijen sunumu ve miyokardın oksijen gereksinimi arasındaki dengesizlik gibi mekanizmalar COVID-19 enfeksiyonlarında kardiyak hasara neden olmaktadır. Enfeksiyona bağlı gelişen KVS hasarı haricinde, tedavide kullanılan bazı ilaçların da KVS üzerine yan etkileri olduğu göz ardı edilmemelidir.

Çıkar Çatışması: Yoktur.

Finansal Destek: Yoktur. 
Conflict of Interest: None.

\section{Funding: None.}

\section{KAYNAKLAR}

1. Wang D, Hu B, Hu C, et al. Clinical Characteris- tics of 138 Hospitalized Patients With 2019 Novel Coronavirus-Infected Pneumonia in Wuhan, China. JAMA. 2020 Feb 7. [Epub ahead of print]. [CrossRef]

2. Huang $C$, Wang $Y$, Li $X$, et al. Clinical features of patients infected with 2019 novel coronavirus in Wuhan, China. Lancet. 2020;395:497-506. [CrossRef]

3. Guan WJ, Ni ZY, Hu Y, et al. Clinical Characteristics of Coronavirus Disease 2019 in China. N Engl J Med. 2020 Feb 28. [Epub ahead of print]. [CrossRef]

4. Richardson S, Hirsch JS, Narasimhan M, et al. Presenting Characteristics, Comorbidities, and Outcomes Among 5700 Patients Hospitalized With COVID-19 in the NewYork City Area. JAMA. 2020. [CrossRef]

5. Palmieri L, Andrianou X, Bella A, et al. Characteristics of COVID-19 patients dying in Italy Report based on available data on March 20 th, 2020 . COVID-19 Surveillance Group. Available at: https://www.epicentro.iss.it/coronavirus/ bollettino/Report-COVID-2019_20_marzo_eng.pdf. Accessed Mar 23, 2020.

6. Zhou F, Yu T, Du R, et al. Clinical course and risk factors for mortality of adult inpatients with COVID-19 in Wuhan, China: a retrospective cohort study. Lancet. 2020:S01406736;30566-3.

7. American College of Cardiology. Troponin and BNP Use in COVID-19. Available at: https://www.acc.org/latest-incardiology/articles/2020/03/18/15/25/troponin-and-bnp use-in covid19?utm_source=accupdate\&utm medium=email_newsletter\&utm_content $=20200320 \& u t m$ campaign=accupdate. Accessed Mar 23, 2020.

8. Tsai SH, Lin YY, Chu SJ, Hsu CW, Cheng SM. Interpretation and use of natriuretic peptides in non-congestive heart failure settings. Yonsei Med J. 2010;51:151-63. [CrossRef]

9. Bajwa EK, Januzzi JL, Gong MN, Thompson BT, Christiani DC. Prognostic value of plasma $\mathrm{N}$-terminal probrain natriuretic peptide levels in the acute respiratory distress syndrome. Crit Care Med. 2008;36:2322-7. [CrossRef]

10. Caforio AL, Pankuweit $S$, Arbustini E, et al. Current state of knowledge on aetiology, diag- nosis, management, and therapy of myocarditis: a position statement of the European Society of Cardiology Working Group on Myocardial and Pericardial Diseases. Eur Heart J. 2013;34:2636-48. [CrossRef]

11. Wang D, Li S, Jiang J, et al. Chinese society of cardiology expert consensus statement on the diagnosis and treatment of adult fulminant myocarditis. Sci China Life Sci.2019;62:187202. [CrossRef]

12. Zhang JJ, Dong X, Cao YY, et al. Clinical characteristics of 140 patients infected with SARS-CoV-2 in Wuhan, China. Allergy.
2020 Feb 19. [Epub ahead of print]. [CrossRef]

13. Zhou P, Yang $X L$, Wang $X G$, et al. A pneumonia outbreak associated with a new coronavirus of probable bat origin. Nature. 2020;579:270-3. [CrossRef]

14. Deshotels MR, Xia H, Sriramula S, Lazartigues E, Filipeanu $\mathrm{CM}$. Angiotensin II mediates angiotensin converting enzyme type 2 internalization and degradation through an angiotensin II type I receptor-dependent mechanism. Hypertension. 2014;64:1368-75. [CrossRef]

15. Laurent S, H Lip GY, McManus R, et al. 2018 ESC/ESH Guidelines for the management of arterial hypertension. [cited 2020 Mar 24]; Available from: https://academic.oup. com/eurheartj/article-abstract/39/33/3021/5079119.

16. Mancia G, Rea F, Ludergnani M, Apolone G, Corrao G. ReninAngiotensin-Aldosterone System Blockers and the Risk of Covid-19. NEJM. 01/05/2020. [CrossRef]

17. Welt FGP, Shah PB, HD Aronow, et al. from the American College of Cardiology's (ACC) Interventional Council and the Society of Cardiovascular Angiography and Intervention (SCAI) Journal of the American College of Cardiology. March 2020. [CrossRef]

18. Romaguera R, Cruz-Gonzales I, Ojeda S, et al. Consensus document of the Interventional Cardiology and Heart Rhythm Associations of the Spanish Society of Cardiology on the management of invasive cardiac proce- dure rooms during the COVID-19 coronavirus outbreak. Revista Espanola de Cardiologia. Mar 3, 2020. [Epub ahead of print]. [CrossRef]

19. Karmpaliotis D, Kirtane AJ, Ruisi CP, et al. Diagnostic and prognostic utility of brain natriuretic Peptide in subjects admitted to the ICU with hypoxic respiratory failure due to noncardiogenic and cardiogenic pulmonary edema. Chest. 2007;131:964-71. [CrossRef]

20. Coronavirus Disease 2019 (COVID-19) Provides Potent Reminder of the Risk of Infectious Agents. Available at: https://www.acc. org/latest-in-cardiology/ articles/2020/03/01/08/42/feature-coronavirus-disease2019-covid-19-provides-potent-reminder-of-the-risk-ofinfectious-agents. Acessed Mar 24, 2020.

21. Hoffmann M, Kleine-Weber $H$, Schroeder S, et al. SARSCoV-2 Cell Entry Depends on ACE2 and TMPRSS2 and Is Blocked by a Clinically Proven Protease Inhibitor. Cell. 2020 Mar 4. [Epub ahead of print]. [CrossRef]

22. Khobragade SB, Gupta P, Gurav P, Chaudhari G, Gatne MM, Shingatgeri VM. Assessment of proarrhythmic activity of chloroquine in in vivo and ex vivo rabbit models. J Pharmacol Pharmacother. 2013;4:116-24. [CrossRef]

23. Arunachalam K, Lakshmanan S, Maan A, Kumar N, Dominic P. Impact of Drug Induced Long QT Syndrome: A Systematic Review. J Clin Med Res. 2018;10(5):384-90. [CrossRef]

24. https://www.acc.org/latest-in-cardiology/ articles/2020/03/27/14/00/ventricular-arrhythmia-risk-dueto-hydroxychloroquine-azithromycin-treatment-for-covid-19

25. Sağlık Bakanlığı COVID-19 (SARS-CoV-2 ENFEKSiYONU) REHBERI (14.04.2020) Bilim Kurulu Çalışması. 